Insert the tille of the workshop here

\title{
Nanotechnology unbolting new avenues for targeted delivery of cancer therapeutics: A brief overview
}

\author{
Kunal Pal ${ }^{a, b^{*}}$ Debbethi Bera ${ }^{c, d}$
}

${ }^{a}$ Department of Life Science and Biotechnology, Jadavpur University, Kolkata-700032, India.

${ }^{b}$ Division of Molecular Medicine and Centre for Translational Research, Bose Institute, Kolkata700056, India.

${ }^{c}$ Centre for Interdisciplinary Research and Education, 404B, Jodhpur Park, Kolkata-700068, India. ${ }^{d}$ Department of Physics, Jadavpur University, Kolkata-700032, India.

\begin{tabular}{|l|l|} 
Graphical Abstract & $\begin{array}{l}\text { Abstract. } \\
\text { The particles within the nanoregime are } \\
\text { quite smaller (100- 10,000 times) than } \\
\text { human cells but are comparable to that of } \\
\text { biomolecules like enzymes and receptors. } \\
\text { The nanoparticles smaller than } 50 \text { nm can } \\
\text { easily pervade into most cells, and those } \\
\text { particles smaller than } 20 \text { nm can easily } \\
\text { escape into the circulation through the } \\
\text { blood vessels. Nanoparticles are quite } \\
\text { conducive to be fabricated appropriately to } \\
\text { serve as a device/vehicles of important } \\
\text { therapeutic genes or drugs specifically to } \\
\text { the cancer cells avoiding any hazardous }\end{array}$ \\
collmembrne
\end{tabular}









\section{Introduction}

Nanotechnology can exert immense impact on cancer therapy as it directly aids in the delivery of the chemotherapeutic drugs. The therapeutic efficacy of all the commonly used drugs can be augmented considerably through the proper utilization of nanotechnology[ Barett et al 2004].These approaches will help in delivering the drug or therapeutics specifically to the target site without hampering the other cells [Vasir et al 2005,Kipp,2004].Furthermore those drugs which have previously failed clinical trials could be readministered after combining with appropriate nanotechnological measures [Rabinow,2004]. Nano drug delivery system could help in getting over a lot of impediments like hydrophobicity( solubility is low) of major drugs lowers their therapeutic efficacy. The encapsulation of these drugs within the hydrophilic nanovehicles improves their solubility which in turn also enhances their bioavilability and their therapeutic efficiency.Further these drugs could also be encapsulated within the organic or lipid nanoparticles that prolongs their circulation time The half life of a therapeutic agent in the circulation is enhanced by manyfolds after encapsulating it within nano-liposomes. [Hornan and Rieger 2001, Torchilin,2005]. In the case of central nervous system cancers, Different drugs are unable to reach the tumor site by overcoming the blood- brain barrier.On the other hand,drug encapsulated nanoparticles have shown great efficiency in crossing this barrier and transporting the drug to the brain tumors.

The encapsulation of an anticancer drug within a nanoparticle and its subsequent targeting to a particular site helps in enhancing its therapeutic efficacy and also diminishes its toxicity to a 
graet extent. [Brannon-Peppas and Blanchette 2004; Ravikumar,2000]. For example,the integrin conjugated lipid nanoparticle were able to deliver genes as well as drugs specifically to the angionenic blood vessel in case of tumor induced mice.This targeted nanoparticle was able to induce apoptosis and caused significant primaer and metastatic tumor regression [Hood et al 2002]. The primary attributes of the nanoparticle-mediated drug delivery is their potential to augment bioavailability, enhance the sustained release of the drugs and also aid in specifically delivering the drug to the target site [Dubin,2004;Dass and Su 2001; Drummond et al 1999]. These delivery could be effectively integrated within the pulmonary therapies [Courrier et al 2002] in the form of emissaries of therapeutic genes[Senior 1998], and also in increasing the stability of the drugs that are prone to degeneration[LaVan et al 2002,2003]. Different physiological charecteristics like the blood brain barrier,the divaricating pulmonary system and the compact epithelial junctions of the skin pose a steep impediment for the drugs to reach their desired location. These nano drug carriers parvade these obstacles and transport the drug to the target site. The maximum efficacy for pulmonary drug delivery is achieved by particles with size $<100 \mathrm{~nm}$ [Courrier et al 2002]. The particles around $100 \mathrm{~nm}$ exhibit enhanced gastrointestinal absorption[Desai,1996; Hussain et al 2001] and the particles of $50 \mathrm{~nm}$ size display very high amount of trancutaneous permeation[Kohli and Alpar, 2004]. These nanoparticles traversing through the pulmonary tract could create a problem if they are exhaled. The use of larger, compartmental or multilayered drug carrier sytem could improve this pulmonary delivery. For example, the outer layers of the nanovehicles could be made in such a way that they erode while traversing the pulmonary tract. As this carrier penetrates furher, the biodegradable components of the carrier will fully degenerate triggering the release of the drugs into the lung. Biodegradable nanoparticles composed of gelatin and humanserum albumin function as promising pulmonary drug 
carrier[Brzoska et al 2004].

The nanoparticles are able to impregnate the tumor tissue through their characteristic tumor microvasculate which characteristically contains pores from 100-1000 nms. Hence these Nanoscale drug delivery architectures are able to penetrate tumors due to the discontinuous, or"leaky," nature of the tumor microvasculature, which typically contains pores ranging from 100 to $1000 \mathrm{~nm}$ in diameter. These pores provide the ideal entry points for the nanoparticles. These nanoparticles can be fabricated appropriately for attained effective drug delivery.

The different nanostructures like solid spheres, hollow spheres, tubes,porous particles, bifurcating structures are utilized for the purpose of drug delivery. The different types of fabrication methods are employed for the development of various kinds of nanoparticles. This encompasses vapor deposition [Mamalis et al 2004], molecular self-assembly [Zhang,2002], nanomanipulation [Hansma et al 2004], bioaggregation [Mirkin et al 1996], photochemical patterning[Cui,2003], molecular imprinting[Cui,2003], layer-by-layer electrostatic deposition [Ai,2002;Ai,2003].

\section{Nanovehicles that are commonly used for the delivery of therapeutics}

The nanocarriers that are widely used as vehicles for the delivery of therapeutics comprises are usually conjugated with a targeting moiety.Different varieties of nanocarriers are widely used like liposomes, micelles, carbon nanotubes, dendrimers, nanoshells etc. The therapeutic agent can be attached with the nanocarrier through the proceeses of entrapping,covalent binding,encapsulation or adsorption. [Vasir et al 2005; Horn and Reiger,2001]. The metal organic frameworks has been predominantly used in several biomedical applications such as adsorption, biosensing and catalysis [Hu et al 2014,Kennedy et al 2013,Huxford et al 2010]. Among the differet metal organic frameworks, the Isoreticular Metalloorganic Frameworks (IRMOFs) have been widely utilized for the delivery of chemotherapeutic 
agents [Kundu et al 2011,Rocca et al 2014]. Liposomes are composed of lipid bilayers where the core can be either hydrophilic or hydrophobic depending on the number of lipid bilayers[Cui,2003;Ai,2002]. Liposomes having a single lipid bilayer contain an aqueous core for entrapping the hydrophilic drugs. Liposomes that possesses more than a single bilayer can encapsulate the hydrophobic(lipid soluble)drugs [Rosiak et al 2003,Pricl et al 2003]. These liposomes are coated with polyethylene glycol (PEG) for ensuring their stability in the physiological conditions. [RaviKumar,2000; Brzoska et al 2004]. The liposomes are coated with hyaluronan (HA) to prolong their circulation time in in vivo and augments its targeting to the overexpressing the HA receptors [Panyam J and Labhasetwar, 2003;Panyam et al 2003]. Liposomes can be conjugated with either antibodies or ligands for the purpose of active targeting to the selected target sites[Nugent $\boldsymbol{e t}$ al 1998, Katare et al 2003]. They are biodegradable,non antigenic and have quite a high transport rate [Lee $\boldsymbol{e t}$ al 2002]. These liposomes can be fabricated $\mathrm{pH}$ responsive drug delivery and also thermotherapy [Rosiak et al 2003,Pricl et al 2003,Namazi and Adeli,2004]. The dendrimers are three dimensional divaricating structures with a multifunctional core which are either synthetic or are composed of elements like amino acids, sugars, and nucleotides[Cloninger,2002]. The characteristic branching points of the dendrimer aids in conjugating different hydrophobic and hydrophilic molecules such as therapeutic genes, drugs, anticancer agents, and so forth [Prinz et al 2003, Tao et al 2003, Chen et al 2004].. Dendrimers in combination with other polymers like used in drug delivery studies typically incorporate one or more of the following polymers like polyamidoamine (PAMAM)[Desai,1996;Cui et al 2003], melamine,poly (L-glutamic acid) (PG), polyethyleneimine(PEI), poly (propylene imine), and poly(ethylene glycol) (PEG) [Mamalis et al 2004]. Have been widely employed in the delivery of anticancer drugs.

The micelles are spherical structures where molecules with a central hydrophobic core and the periphery is hydrophilic remain in close contact with the liquid environment just adjacent to the core. 
Micelles are effective carrier for the delivery of lipid soluble drugs which are encapsulated in their hydrophobic core[Li et al 2004]. The nanoparticles can be conjugated with appropriate ligands or antibodies for targeting them to the desired site.

Targeting ligands or antibodies can be attached to the surface [Li et al 2004].,Fullerenes(also called bucky balls) and nanotubes. These nanotubes are fabricated to make them hydrophilic and are conjugated to the targeting ligands like peptides, nucleic acidsand therapeutic agents [Weis et al 2002]. Nanotubes can be single walled or multiwalled [Leoni et al 2004] and widely used for the delivery chemotherapeutic agents. The different polymers that are used includes poly (alkyl cyanoacrylates),poly(methylidenemalonate) and polyesters such as poly( $\varepsilon$-caprolactone),poly(lactic acid),poly(glycolic acid) and their copolymers like PLGA are most extensively researched due to their biocompatibility and biodegradability [Mirakabad et al 2014]

\section{Natural polymers as emerging carriers of therapeutics}

Natural polymers are generally obtained from plant and animal kingdom. Most of the natural polymers are high molecular weight; water soluble polymers made up of monosaccharide units and joined by glycosides linkage [Farooq et al 2004]. Gummy exudates of natural polymers such as protein, enzyme, muscle, fiber, and polysaccharide have been used to formulate various pharmaceutical products [Farooq et al 2014,Krishna et al 2011]. The well-known natural polymers are gelatin, Gum Acacia, aloe mucilage, guar gum, karaya gum, bhara gum, sodium alginate, locust bean gum, Hibiscus mucilageand linseed mucilage. These natural polymers are applicable in different pharmaceutical dosage forms like matrix controlled systems, microspheres, nanoparticles, buccal films and viscous liquid formulations [Krishna et al 2011]. The specific application of natural polysaccharides in pharmaceutical preparation is to help in the processing of drug delivery systems during its manufacturing, protection, enhancement of stability, bioavailability and patient acceptability [Malviya et al 2011,Sujitha et al 2012]. Gums have various pharmaceutical applications such as suspending 
agent for insoluble solid component in mixture, emulsifying agent for resin oils and adhesive in troche masses and pills [Wang et al 2013].

(a)

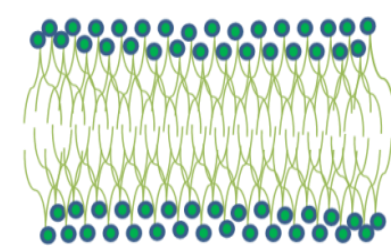

(d)



(b)

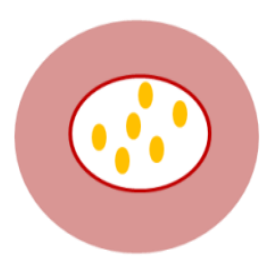

(e)

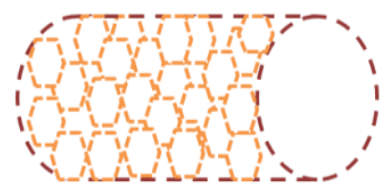

(c)

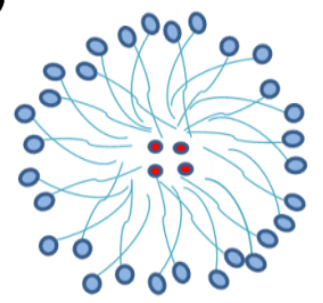

(f)

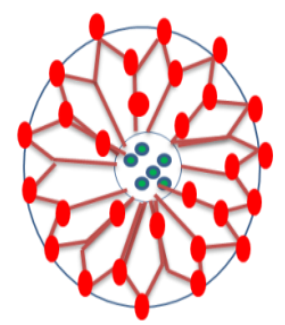

Fig-1.1.Structures of (a) liposome bilayer, (b) liposome, (c) micelle, (d) polymeric nanoparticles, and (e) dendrimer.

\section{Targeted drug delivery Systems}

The concept of designing a targeted delivery was first conceived by a microbiologist Paul Ehrlich. Targeted drug delivery involves the transport and accumulation of therapeutic agent to a desired site in without hampering the normal cells, thus enhancing the therapeutic efficacy of that agent . The primary features of targeted delivery are:

$>$ It should be nontoxic, biocompatible, biodegradable, and exhibit physicochemical stability in both in vivo and in-vitro environments.

The distribution of the drug should be limited to the desired site(cells, tissues,organs 
or uniform capillary distribution.)

The rate of drug release should be controllable and predictable.

The drug distribution should be affected by the drug release.

$>$ The amount of drug released by the system should be sufficient for therapy in the desired site.

The drug leakage during transport should be restricted.

$>$ The carriers must be biodegradable or readily eliminated from the body without exerting any hazardous effect and they should not temper the diseased site.

$>$ The synthesis of these drug delivery system should be reasonably facile, high yielding and cost effective.

Targeted drug delivery has been segregated into different categories considering the attributes of the target cells and also the type of targeting ligand.

\section{Active Targeting.}

In case of active targeting, nanoparticles containing the chemotherapeutic agents are designed in such a way such that they directly interact with the diseased cells. The active targeting is solely based on the recognition of the cellular biomolecules. Henceforth the nanoparticle are fabricated by attaching with the targeting agents in order to recognize the molecular patterns of the cancer cells which in turn helps in the delivery of the therapeutics to the desired site. These fabricated nanoparticles target the cancerous cells either through the process of ligand receptor interaction or by antibody-antigen recognition. These targeted delivery systems mainly comprise of the major components like, (i) a therapeutic agent (ii) a targeting ligand to enhance the penetration and (iii) a carrier. The cancerous cells have some unique attributes 
like some specific receprors are overexpressed on their surface that help in discriminating them from the healthy cells .The conjugation of the specific ligands on the surface of nanoparticles enable them to specifically target the cancer cells. These targeted nanoparticles specifically bind with the receptors, undergo receptor-mediated endocytosis or phagocytosis, resulting in the internalization of the encapsulated drug and is rapidly cleared by the reticuloendothelial system (RES). Several endeavors have been made to exploit these ligand receptor interactions for the purpose of biomedical applications [Dubin et al 2004].

Passive Targeting- Nanoparticles can also target cancer through passive targeting.In cancerous cells there are anomalies in the blood vessels creating wide and leaky blood vessels near the endothelial which are promoted by angiogenesis [Kannan et al 2004]. The size of the pores in leaky endothelial cells ranges from 100 to $780 \mathrm{~nm}$ [Pricl $\boldsymbol{e t}$ al 2003; Namzi and Adeli 2004,Cloninger; 2002]. Hence the nanoparticles with that size range can easily penetrate through that endothelial pore[Kannan et al 2004].Henceforth the nanoparticles can be specifically to the capillary endolthelium for delivering drug to the desired organ. These nanoparticles can penetrate the tumor cells by passive diffusion or convection. The tumor cells are devoid of defined lymphatic system having leaky vessels which in turn facilitates the process of passive diffusion. Hence the drugs that penetrate with the tumor interstitum have prolonged retention times and this feature is regarded as enhanced permeability and retention (EPR) effect and this aids in the accumulation of drug with the tumor interstitium [ Panyam et al 2003,Nugent et al 1998].

Inverse Targeting: This type of targeting attempts involves the circumventing of passive uptake of colloidal carrier by RES and therefore this targeting is regarded as inverse targeting. The inverse targeting is achieved by suppressing the normal functioning of RES through pre-injection of bare colloidal carriers or macromolecules like dextran sulphate 
[IIlium et al., 1989]. This leads to the saturation of RES which in turn hinders the normal defence mechanism.

Dual Targeting: In this targeting approach the vehicle possess intrinsic therapeutic activity which thus augments the therapeutic efficacy of a drug. For example, a vehicle having its own anticancer activity can be encapsulated with a anticancer drug and the cumulative synergistic effect of that drug was evaluated [Gupta et al., 2000].

Double Targeting: When temporal and spatial methodologies are combined to target a carrier system, then that targeting strategy is regarded as double targeting. Spatial placement relates to targeting drugs to specific organs, tissues, cells. On the other hand, the temporal delivery refers to the regulation of the drug delivery rate to the desired site.

\section{Folate receptor mediated drug delivery}

Folic acid (FA) is a vitamin B complex which plays a pivotal role in cell viability through the biosynthesis of nucleic and amino acids. FA is a natural ligand of folate receptor (FR) and the binding affinity of FA for FR is approximately $\mathrm{K}_{\mathrm{d}} \sim 10^{-10} \mathrm{M}$ (Pan et al 2009). Folic receptors are over-expressed in different types of primary as well as metastatic human cancers like the lung, the kidney, endometrium, ovary, colon, brain and triple negative breast cancer cells [ Zhang et al 2010,Lederman et al 2015, Cheung et al 2016 ].

Additionally the advancement in the stages/grades of cancer is closely associated with the increase in the density of FRs.Doxorubicin (DOX) is a widely used highly potent anticancer agent for a variety of tumors. But the doxorubicin also induces dose-dependent cardiotoxicity which restricts its successful clinical applications. Zhang et al successfully developed a targeted 
drug delivery system of Doxorubicin by employing poly-(3-hydoxybutyrate-co-3-hydroxy octanoate) as a vehicle and Folic Acid as a active targeting ligand [Zhang et al., 2010].

\begin{tabular}{|c|c|c|c|c|}
\hline $\begin{array}{ll}\text { Types of } \\
\text { vehicles }\end{array}$ & $\begin{array}{l}\text { Anticancer } \\
\text { drug }\end{array}$ & Targeting agent & $\begin{array}{l}\text { Name of the } \\
\text { polymers used }\end{array}$ & Outcome \\
\hline $\begin{array}{l}\text { Polymeric } \\
\text { nanoparticles }\end{array}$ & Cystatin & $\begin{array}{l}\text { Cytokeratin specific } \\
\text { monoclonal antibody }\end{array}$ & $\begin{array}{l}\text { Poly-(D-L- lactide } \\
\text { co-glycolide) and } \\
\text { polyethylene glycol }\end{array}$ & $\begin{array}{l}\text { Prevent } \\
\text { metastasis }\end{array}$ \\
\hline $\begin{array}{l}\text { Polymeric } \\
\text { nanoparticles }\end{array}$ & Paclitaxel & Monoclonal antibody & Polylactic Acid & $\begin{array}{l}\text { Selective } \\
\text { targeting }\end{array}$ \\
\hline $\begin{array}{l}\text { Polymeric } \\
\text { nanoparticles }\end{array}$ & Paclitaxel & Folic acid & $\begin{array}{l}\text { Polylactic Acid and } \\
\text { polyethylene glycol }\end{array}$ & $\begin{array}{l}\text { Enhanced } \\
\text { drug } \\
\text { accumulation } \\
\text { in tumor }\end{array}$ \\
\hline Dendrimers & ---- & Folic acid & Polyamidoamine & $\begin{array}{l}\text { Increased } \\
\text { cellular } \\
\text { uptake }\end{array}$ \\
\hline Nanoshell & Docetaxel & Folic acid & $\begin{array}{l}\text { Biodegradable } \\
\text { polymer }\end{array}$ & $\begin{array}{l}\text { Sustainable,c } \\
\text { ontrolled and } \\
\text { targeted } \\
\text { delivery }\end{array}$ \\
\hline Dendrimer & $\begin{array}{l}\text { Small } \\
\text { interfering } \\
\text { RNA(siRNA) }\end{array}$ & $\begin{array}{l}\text { Luteinising hormone } \\
\text { releasing } \\
\text { hormone(LHRH)peptide }\end{array}$ & $\begin{array}{l}\text { Poly(propyleneimine) } \\
\text { and polyethylene } \\
\text { glycol }\end{array}$ & $\begin{array}{l}\text { High } \\
\text { specificity }\end{array}$ \\
\hline Nanoparticle & Paclitaxel & Folic acid & $\begin{array}{l}\text { Poly-(D-L- lactide } \\
\text { co-glycolide) }\end{array}$ & $\begin{array}{l}\text { Inhibition of } \\
\text { P- } \\
\text { glycoprotein }\end{array}$ \\
\hline $\begin{array}{l}\text { Polymer } \\
\text { micelle }\end{array}$ & Doxirubicin & Folic acid & $\begin{array}{l}\text { PEG-co-(lactic co- } \\
\text { glycolic acid) }\end{array}$ & $\begin{array}{l}\text { Increased } \\
\text { cellular } \\
\text { uptake and } \\
\text { cytotoxicity }\end{array}$ \\
\hline $\begin{array}{l}\text { Polymer } \\
\text { micelle }\end{array}$ & Doxirubicin & Folic acid & $\begin{array}{l}\text { PEG- poly(aspartate } \\
\text { hydrazone) }\end{array}$ & $\begin{array}{l}\text { Increased } \\
\text { endocytotic } \\
\text { cellular } \\
\text { uptake }\end{array}$ \\
\hline
\end{tabular}


Table-1.1. Representing the different nanocarriers that has been formulated with positive results in the recent investigations. 


\section{Conclusions}

These targeted nanoparticles face a steep challenge in releasing the drugs to the cancer cells since the hydrolytic enzymes residing in the lysosomes of the cells cause damage to both the nanoparticles and the encapsulated drugs. The tumors characteristically have a lower $\mathrm{pH}$ and this attribute can be exploited while designing the carriers. Thus the carriers which are responsive to the alterations in the $\mathrm{pH}$ and change their solubility at lower $\mathrm{pH}$ is quite conducive for drug delivery. A pH responsive nanoparticle typically comprises of a shell and a core The core-shell nanoparticles are designedth in a way that their lower critical solution temperature (LCST) is dependent on the ambient $\mathrm{pH}$. The lower $\mathrm{pH}$ near the tumor cells causes a drastic alteration in the LCST of the coreshell nanoparticles which leads to its structural degradation that eventually stimultes the unleashing of the therapeutics. The conjugation of a targeting moity helps in specifically targeting these nanoparticles to the cancer cells. [Neerman et al 2004]. A wide range of biodegradable nanoprticles have been designed from the the copolymers of poly(d,1-lactide-co-glycolide) which are endowed with the ability to deliver different therapeutic agents like DNA.The researchers have also developed thermoresponsive, $\mathrm{pH}$-responsive by combining biodegradable poly (d,l-lactide) o, $\mathrm{N}$-isopropyl acrylamide and methacrylic acid [Mirakabad $\boldsymbol{e t}$ al 2014]. These carrier systems are able to deliver the hydrophobic drug specifically to the cancer cells [Tansey et al 2004;Paleos et al 2004].

\section{References}

Ai H (2002). Electrostatic layer-by-layer nanoassembly on biological microtemplates: platelets. Biomacromolecules, 3: 560-564.

Ai H (2003). Biomedical applications of electrostatic layerby- layer nano-assembly of polymers, enzymes, and nanoparticles, Cell Biochem. Biophys. 39: 23-43.

Barrett JC et al. (2004). Laser captures micro dissection, microarrays and the precise definition of a cancer cell. Expert Rev. Mol. Diagn., 4: 831840.

Brannon-Peppas L and Blanchette JO (2004).Nanoparticle and targeted systems for cancertherapy, Adv. Drug Delivery Rev., 56: 1649-1659. 
Brzoska M, LangerK, Coester C, Loitsch S, Wagner TOF and Mallinckrodt CV (2004). Incorporation of biodegradable nanoparticles into human airway epithelial cells-in vitro study of the suitability as a vehicle for drug or gene delivery in pulmonary diseases, Biochem Biophys Res. Commun., 318:562570.

Chen JF, Ding HM, Wang JX and Shao L (2004).Preparation and characterization of porous hollow silica nanoparticles for drug delivery application,Biomaterials, 25: 723-727.

Cloninger MJ (2002). Biological applications of dendrimers, Curr. Opin. Chem. Biol., 6: 742-746.

Cortez-Retamozo V, Backmann N, Senter PD,Wernery U, De Baetselier P and Muyldermans S etal. (2004). Efficient cancer therapy with ananobody-based conjugate, Cancer Research. 64:

Courrier HM, Butz N and Vandamme TF (2002). Pulmonary drug delivery systems: recent developments and prospects, Crit. Rev. Ther. Drug Carrier Syst., 19: 425-498.

Cui D (2003). Advance and prospect of bionanomaterials, Biotechnol Prog., 19: 683-692.

Dass CR and Su T (2001). Particle-mediated intravascular delivery of oligonucleotides to tumors: associated biology and lessons from genotherapy. Drug Delivery, 8: 191- 213.

Desai MP (1996). Gastrointestinal uptake of biodegradable microparticles: effect of particle size,Pharm. Res., 13: 1838-1845.

Drummond DC, Meyer O, Hong K and Kirpotin DB (1999). Papahadjopoulos. Optimizing liposomes for delivery of chemotherapeutic agents to solid tumors, Pharmacol Rev., 51: 691-743.

Dubin CH (2004). Special delivery: pharmaceutical companies aim to target their drugs with nano precision, Mech. Eng. Nanotechnol., 126(Suppl.):10-12.

Farokhzad OC, Jon S, Khademhosseini A, Tran TN,Lavan DA and Langer R (2004). Nanoparticleaptamer bioconjugates: a new approach for targeting prostate cancer cells. Cancer Res., 64:7668-7672.

Gillies ER and Frechet J.M. (2005). Dendrimers and dendritic polymers in drug delivery. Drug Discov. Today, 10: 35-43.

Hansma HG, Kasuya K and Oroudjev E (2004). Atomic force microscopy imaging and pulling of nucleic acids, Curr. Opin. Struct. Biol., 14: 380-385.

Hood JD et al. (2002). Tumor regression by targeted gene delivery to the neovasculature, Science, 296: 2404-2407.

Horn D and Rieger J (2001). Organic nanoparticles in theaqueous phase-theory, experiment, and use.Angew. Chem. Int. Ed., 40: 4330-4361.

Hughes G. A. (2005) Nanostructure-mediated drug delivery Nanomedicine: Nanotechnology, Biology and Medicine 1(1): 22-30. 
Hussain M, Shchepinov M, Sohail M, Benter IF,Hollins AJ and Southern EM (2004). A novel anionic dendrimers for improved cellular delivery of antisense oligonucleotides, J. Controlled Release,99: 139155.

Hussain N, Jaitley V and Florence AT (2001). Recent advances in the understanding of uptake of microparticulates across the gastrointestinal lymphatics. Adv. Drug Delivery. Rev., 50: 107-142.

Kannan S, Kolhe P, Raykova V, Glibatec M, Kannan RM and Lieh-Lai M (2004). Dynamics of cellular entry and drug delivery by dendritic polymers into human lung epithelial carcinoma cells, J. Biomat. Sci. Polymer Ed., 15: 311-330.

Karhanek M, Kemp JT, Pourmand N, Davis RW and Webb CD (2005). Single DNA molecule detection using nanopipettes and nanoparticles. Nano Lett.,5: 403-407.

Katare YK, Panda AK, Lalwani K, Haque IU and Ali MM (2003). Potentiation of immune response from polymerentrapped antigen: toward development of single dose tetanus toxoid vaccine. Drug Delivery,10: 231-238.

Kipp JE (2004). The role of solid nanoparticle technology in the parenteral delivery of poorly watersoluble drugs. Int. J. Pharm., 284: 109-122.

Kohli AK and Alpar HO (2004). Potential use of nanoparticles for transcutaneous vaccine delivery:effect of particle size and charge. Int. J. Pharm.,275: 13-17.

LaVan DA, Lynn DM and Langer R (2002). Moving smaller in drug discovery and delivery. Nat. Rev. Drug Discovery, 1: 77-84.

LaVan DA, McGuire T and Langer R (2003). Smallscale systems for in vivo drug delivery. Nat. Biotechnol., 21: 1184-1191.

Lee KE, Kim BK and Yuk SH (2002). Biodegradable polymeric nanospheres formed by temperature induced phase transition in a mixture of poly (lactide-co-glycolide) and poly (ethylene oxide)poly(propylene oxide) - poly (ethylene oxide) triblockcopolymer. Bio macromolecules. 3: 1115-1119.

Leoni L and Desai TA (2004). Micromachined biocapsules for cell-based sensing and delivery. Adv. Drug Delivery, Rev., 56: 211-229.

Li X, St John J, Coffer JL, Chen Y, Pinizzotto RF and Newey J et al. (2000). Porosified silicon wafer structures impregnated with platinum anti-tumor compounds: Fabrication, characterization, and diffusion studies, Biomed. Microdevices, 2: 265-272.

Li ZZ, Wen LX, Shao L and Chen JF (2004).Fabrication of porous hollow silica nanoparticlesand their applications in drug release control. J.Controlled Release, 98: 245- 254.

Lockman PR, Mumper RJ, Khan MA and Allen DD(2002). Nanoparticle technology for drug delivery across the blood-brain barrier. Drug Dev. Indust. Pharm., 28: 1-13.

Mamalis AG, Vogtländer LOG and Markopoulos A (2004). Nanotechnology and nanostructured materials: trends in carbon nanotubes. Precision Eng., 28: 16-30. 
Martin CR and Kohli P (2003). The emerging field of nanotube biotechnology. Nat. Rev. Drug Discovery, 2: 29-37.

Mirkin CA, Letsinger RL, Mucic RC and Storhoff JJ (1996). A DNA method for rationally assembling nanoparticles into macroscopic materials. Nature, 382: 607-609.

Moselhy J, Wu XY, Nicholov R and Kodaria K (2000). In vitro studies of the interaction of poly (NIPAm/MAA) nanoparticles with protein and cells. J. Biomat. Sci. Polymer Ed., 11: 123-147.

Namazi H and Adeli M (2004). Dendrimers of citric acid and poly (ethylene glycol) as the new drugdelivery agents. Biomaterials, 26: 1175-1183.

Neerman MF, Zhang W, Parrish AR and Simanek EE (2004). In vitro and in vivo evaluation of a melamine dendrimer as a vehicle for drug delivery,Int. J. Pharm., 281: 129-132.

Nugent J, Wan Po A.L. and Scott EM (1998). Design and delivery of non-parenteral vaccines, J. Clin.Pharm. Ther., 23: 257-285.

Paleos CM, Tsiourvas D, Sideratou Z and Tziveleka L (2004). Acid- and salt-triggered multifunctional poly (propylene imine) dendrimer as a prospective drug delivery system. Biomacromolecules, 5: 524529.

Panyam J and Labhasetwar V (2003).Biodegradable nanoparticles for drug and gene delivery to cells and tissue. Adv. Drug Delivery Rev.,55: 329-347.

Panyam J, Dali MM, Sahoo SK, Ma W, Chakravarthi SS and Amidon GL et al. (2003). Polymer degradation and in vitro release of a model protein from poly (d, l-lactide-coglycolide) nano- and microparticles. J. Controlled Release, 92: 173-187.

Pricl S, Fermeglia M, Ferrone M and Asquini A(2003). Scaling properties in the molecular structure of threedimensional, nanosize phenylene-based dendrimers as studied by atomistic molecular dynamics simulations. Carbon,41: 2269-2283.

Prinz AV, Prinz V Ya and Seleznev VA (2003).Semiconductor micro- and nanoneedles for microinjections and ink-jet printing. Microelectronic Eng., 67-68: 782-788.

Rabinow BE (2004). Nanosuspensions in drug delivery. Nat. Rev. Drug Discov., 3: 785-796.

Ravi Kumar MN (2000). Nano and microparticles as controlled drug delivery devices. J. Pharm.Pharm. Sci., 3: 234-258.

Rosiak JM, Janik I, Kadlubowski S, Kozicki M,Kujawa P and Stasica P (2003). Nano-, micro- and macroscopic hydrogels synthesized by radiation technique. Nucl. Instruments Methods Phys. Res.B., 208: $325-330$.

Sahoo SK et al. (2003). Nanotech approaches to drug delivery and imaging. Drug Discov. Today, 8:1112-1120. 
Schiffelers RM, Ansari A, Xu J, Zhou Q, Tang Q and Storm G (2004). Cancer siRNA therapy by tumor selective delivery with ligand-targeted stericallystabilized nanoparticle. Nucleic Acids Res., 32:e149.

Senior K (1998). Nano-dumpling” with drug delivery potential. Mol. Med. Today, 4: 321.

Shi W, Sahoo Y, Swihart MT and Prasad PN (2005).Gold nanoshells on polystyrene cores for control of surface plasmon resonance. Langmuir, 21: 1610-1617.

Tansey W, Ke S, Cao XY, Pasuelo MJ, Wallace S and Li C (2004). Synthesis and characterization of branched poly (L-glutamic acid) as a biodegradable drug carrier. J. Controlled Release, 94: 39-51.

Tao SL and Desai TA (2003). Microfabricated drug delivery systems: from particles to pores. Adv. Drug Delivery Rev., 55: 315-328.

Torchilin VP (2005). Recent advances with liposomes as pharmaceutical carriers. Nat. Rev. Drug Discov., 4: 145- 160.

Ulrich KE, Cannizzaro SM, Langer RS and Shakeshelf KM (1999). Polymeric systems for controlled drug release. Chem. Rev., 99: 3181-3198.

Vasir JK et al. (2005). Nanosystems in drug targeting: opportunities and challenges. Curr. Nanoscience, 1: 47-64.

Weis RP, Montchamp JL, Coffer JL, Attiah DG andDesai TA (2002). Calcified nanostructured silicon wafer surfaces for biosensing: effects of surface modification on bioactivity. Dis. Markers, 18: 159165.

West JL and Halas NJ (2003). Engineered nanomaterials for biophotonics applications: improving sensing, imaging, and therapeutics.Annu. Rev. Biomed. Eng., 5: 285-292.

Xie Y and Gao Y (2005). Controlled transdermal delivery of model drug compounds by MEMS microneedle array. Nanomedicine, 1: 184-190.

Yu W, Pirollo KF, Yu B, Rait A, Xiang L and Huang et al. W (2004). Enhanced transfection efficiency of a systemically delivered tumor-targeting immunolipoplex by inclusion of a $\mathrm{pH}$-sensitive histidylated oligolysine peptide. Nucleic Acids Res.,32: 48.

Zhang S (2002). Emerging biological materials through molecular self-assembly. Biotechnol. Adv.,20: 321-339. 
MOL2NET, 2020, 6, ISSN: 2624-5078 